Gaurav Kumar Rose, Raman Soni, Praveen Rishi and Sanjeev Kumar Soni*

\title{
Optimization of the biological synthesis of silver nanoparticles using Penicillium oxalicum GRS-1 and their antimicrobial effects against common food-borne pathogens
}

https://doi.org/10.1515/gps-2018-0042

Received February 6, 2018; accepted July 10, 2018; previously published online August 31, 2018

\begin{abstract}
Biologically synthesized nanoparticles are gaining importance as they offer several advantages, such as the ease with which they can be scaled up, the cost-effectiveness of the process and the green route of production. In this study, silver ( $\mathrm{Ag})$ nanoparticles were biosynthesized using the cellular extract of Penicillium oxalicum GRS-1 and then characterized by ultraviolet visible spectroscopy, X-ray diffraction, field emission scanning electron microscopy, transmission electron microscopy (TEM) and Fourier transform infrared spectroscopy. The biosynthesis of nanoparticles was optimized by following the one factor at a time approach, wherein the temperature of $60^{\circ} \mathrm{C}, \mathrm{pH} 7.0$ and $1.5 \mathrm{~mm}$ silver nitrate $\left(\mathrm{AgNO}_{3}\right)$ concentration were found to be most favorable factors for the production of $\mathrm{Ag}$ nanoparticles. Upon statistical optimization, the maximum production of Ag nanoparticles with a concentration of $136 \mathrm{ppm}$ was achieved at $\mathrm{pH}$ 7.2, $\mathrm{AgNO}_{3}$ concentration $1.975 \mathrm{~mm}$ and $86 \mathrm{~h}$ using the crude cellular extract of $P$. oxalicum GRS-1 having nitrate reductase activity. TEM analysis showed that the Ag nanoparticles were spherical in shape with sizes ranging from 10 to $40 \mathrm{~nm}$. The biosynthesized nanoparticles showed strong antimicrobial activity against the common food-borne, pathogens including Staphylococcus aureus, Escherichia coli and Salmonella typhimurium with respective minimum bactericidal concentrations of 32, 16 and $32 \mu \mathrm{g} / \mathrm{ml}$
\end{abstract}

Keywords: antimicrobial; optimization; Penicillium oxalicum; silver nanoparticles.

\footnotetext{
*Corresponding author: Sanjeev Kumar Soni, Department of Microbiology, Panjab University, Chandigarh-160014, India, e-mail:sonisk@pu.ac.in

Gaurav Kumar Rose and Praveen Rishi: Department of Microbiology, Panjab University, Chandigarh-160014, India

Raman Soni: Department of Biotechnology, D.A.V. College, Chandigarh-160011, India
}

\section{Introduction}

Nanotechnology involves the control of matter at the sub-atomic nanoscale level [1], wherein the properties of matter are altogether different from their plainly visible mass properties [2]. Nanoparticles are the fundamental building blocks for producing numerous nanostructured materials and gadgets. [3]. Nanoparticle production is a vital part of the quickly thriving research endeavors in the fields of nanoscience and nanoengineering [2]. There is a growing urgency of employing environment-friendly technology for nanoparticle production that does not produce toxic wastes. To achieve this, we are inclined to adopt economical production processes, which appear to be of biological origin [2]. Nanoparticles synthesized by a biological approach are more desirable, in copious ways, to those synthesized by chemical methods [4, 5] and has several advantages, including easy scaling up of the procedure, costeffectiveness and its green nature.

Numerous biological agents, including bacteria, yeasts, fungi and plant extracts, play an essential role in remediation of toxic metals through metal ion reduction. These agents can act as eco-friendly nanofactories for the biosynthesis of cadmium, gold and silver nanoparticles [6-9]. Fungi appear to be a good candidate for the biosynthesis of metal nanoparticles because of the presence of a range of bio-catalysts and reducing agents in their cells. Fungi secrete large amounts of proteins compared with bacteria, which results in the biosynthesis of large amounts of nanoparticles. Of the various nanoparticles, Ag nanoparticles have attracted the greatest attention because of their wide range of applications for the welfare of the society [10]. In all the life forms that can biosynthesize Ag nanoparticles, nitrate reductase may be an indispensable part. The reduction mediated by the presence of this enzyme in the organism has been observed to be responsible for the biosynthesis of nanoparticles [11-14].

Ag nanoparticles have emerged as a principal product from the field of nanobiotechnology. Due to the expanding microbial resistance against antibiotics and the evolution of resistant strains, the biosynthesis and use of $\mathrm{Ag}$ 
nanoparticles is an important field of interest for many researchers $[15,16]$. The high efficiency of Ag nanoparticles is mainly due to the scope of a larger surface area to volume ratio for interactions, which facilitate the attachment of Ag nanoparticles to the cell membrane and also penetration inside the bacteria [17-19]. Ag nanoparticles interact with the sulfur, which contains membrane proteins of the bacteria, as well as with the phosphorous, which contains compounds like DNA. The nanoparticles preferably attack the respiratory chain, cell division and finally lead to cell death. The Ag ions are released by the nanoparticles inside the bacterial cells, which intensify their bactericidal activity [20]. Aside from its major use as an antimicrobial agent, Ag nanoparticles are recognized to have the toxic effects in many different species. Therefore, substantial test trials are required to understand the toxicity of such nanoparticles. In the present study, the crude cellular extract from Penicillium oxalicum GRS-1 was successfully employed for the biosynthesis of Ag nanoparticles. Results indicated its inhibitory activity against common food-borne pathogens.

\section{Materials and methods}

\subsection{Microorganism}

The fungal strain of $P$. oxalicum GRS-1, used in the present study, was isolated from soil after an extensive screening of natural biodiversity of Chandigarh City and identified on the basis of microscopic and molecular analysis of $18 \mathrm{~S}$ rDNA sequencing.

\subsection{Production of nitrate reductase by $P$. oxalicum GRS-1 and the biosynthesis of Ag nanoparticles}

Fungal biomass was produced by inoculation with spore suspension $\left(1.7 \times 10^{7}\right.$ spores $\left./ \mathrm{ml}\right)$ from a 4-day old culture of $P$. oxalicum GRS-1 in $50 \mathrm{ml}$ MGYP broth (malt extract, $0.3 \%$; glucose $1 \%$, yeast extract, $0.3 \%$; peptone, $0.5 \%$; pH 5.0) (Hi-Media, Mumbai, India) dispensed in $250 \mathrm{ml}$ Erlenmeyer flasks and incubated on a rotary shaker (Bio-age, India) $\left(150 \mathrm{rpm}, 28^{\circ} \mathrm{C}\right)$ for $96 \mathrm{~h}$. Fungal biomass was filtered and washed properly with distilled water and $10 \mathrm{~g}$ of the same was dispensed in $100 \mathrm{ml}$ of distilled water taken in $250 \mathrm{ml}$ Erlenmeyer flask, incubated on a rotary shaker $\left(150 \mathrm{rpm}, 28^{\circ} \mathrm{C}\right)$ for $48 \mathrm{~h}$. The cell filtrate was obtained by the separation of fungal beads through the whatman filter paper no. 1 and analyzed for nitrate reductase activity. This was then mixed with $\mathrm{AgNO}_{3}$ solution at a final concentration of $1 \mathrm{~mm}$ incubated on a rotary shaker $\left(150 \mathrm{rpm}, 28^{\circ} \mathrm{C}\right)$ for $72 \mathrm{~h}$ and cell filtrate without $\mathrm{AgNO}_{3}$ was used as a control [21]. The transformations of the Ag ions into Ag nanoparticles were monitored by the UVvisible spectrophotometer and the nanoparticles were collected by ultracentrifugation (Hitachi Himac, CS 120GX, Japan) at 100,000 g for $30 \mathrm{~min}$, purified by giving washings in alcohol and stored for further characterization.
2.2.1 Nitrate reductase assay in the cell-free supernatant: The nitrate reductase assay was performed by using the procedure as laid down by Gilliam et al. [22]. The enzyme activity was expressed in terms of International Units (IU) equivalent to the nanomoles $\mathrm{KNO}_{2}$ produced from $\mathrm{KNO}_{3}$ per hour under assay conditions $\left(40^{\circ} \mathrm{C}, \mathrm{pH} 7.5\right)$.

\subsection{Characterization of the Ag nanoparticles}

The nanoparticles were characterized by X-ray Diffraction (XRD) (Panalytical.s X.Pert Pro, Malvern Panalytical, Malvern, UK), field emission scanning electron microscopy (FESEM) (Model JSM6100, Jeol, Peabody, MA, USA), transmission electron microscopy (TEM) (Hitachi, H-7500, Japan) and Fourier transform infrared spectroscopy (FTIR) (Model RZX, Perkin Elmer, Billerica, MA, USA) [23] at the sophisticated analytical instrumentation facility, Panjab University, Chandigarh.

\subsection{Optimization of the biological synthesis of the Ag nanoparticles}

There are several factors that affect the biosynthesis, shape and size of metal nanoparticles. The effect of various factors like $\mathrm{pH}$ and temperature, substrate $\left(\mathrm{AgNO}_{3}\right)$ concentration and biomass concentration on the biosynthesis of Ag nanoparticles was studied by using one variable at a time approach.

\subsection{Statistical optimization of the Ag nanoparticle production by $P$. oxalicum GRS-1 using response surface methodology (RSM)}

The effects of changes in various environmental parameters and their interactions were evaluated by employing a statistical modeling with RSM. RSM uses a statistical approach to assess the effect of changes in the conditions of different environmental factors on Ag nanoparticle production in order to find out the optimum conditions for their production. Three factors, including $\mathrm{pH}\left(\mathrm{X}_{1}\right), \mathrm{AgNO}_{3}$ concentration $\left(\mathrm{X}_{2}\right)$ and incubation time $\left(\mathrm{X}_{3}\right)$, which affect nanoparticle production was chosen for further standardizing the Ag nanoparticle biosynthesis by Penicillium oxalicum GRS-1. A $2^{3}$ factorial central composite trial configuration bringing about 20 trial runs were produced by Design Expert, Version 10.0 (Stat-Ease Inc. Minneapolis, MN, USA). The connection amongst coded and genuine values is depicted by Equation (1)

$$
\begin{aligned}
& X_{i}=\left(X_{i}-X_{0 i}\right) / \delta X_{i}, \\
& I=1,2,3 \ldots \ldots . . j
\end{aligned}
$$

where $\mathrm{X}_{\mathrm{i}}=$ coded (dimensionless) estimation of variable $\mathrm{X}_{\mathrm{i}}$, which is the actual estimation of the ith variable; $X_{0}=$ the value of $X_{i}$ at the center point and $\delta \mathrm{X}=$ is the step change in value. The conduct of the framework was clarified by the following second order polynomial equation:

$$
Y=b_{o}+\Sigma b_{i} x_{i}+\Sigma \Sigma b_{i j} x_{i} x_{j}+\Sigma b_{i i} x_{2} i+e
$$

where $\mathrm{Y}=$ measured reaction; bo, bi, bij and bii are the constant and regression coefficients of the model; $\mathrm{x}_{\mathrm{i}}$ and $\mathrm{x}_{\mathrm{j}}$ are the levels (code values) of independent values and e is random error. The Design Expert, Version 10.0 (Stat-Ease Inc. Minneapolis, MN, USA) was utilized for the regression analysis of the information obtained and to measure 
the coefficients of the regression equation. 3D surface graphs were designed by using the Design expert software to analyze the relationship between the factors. The accuracy of the general ability of the polynomial model was assessed by the coefficient of determination $\left(\mathrm{R}^{2}\right)$. The statistical significance of the model coefficient was evaluated by one-way analysis of variance (ANOVA). The response in all the 20 flasks was expressed in terms of the concentration (ppm) of the biosynthesized Ag nanoparticles.

\subsection{In vitro assessment of the anti-bacterial activity of the Ag nanoparticles}

The inhibitory impact of the Ag nanoparticles against the common food-borne pathogens, including Staphylococcus aureus, Escherichia coli and Salmonella typhimurium, was evaluated by agar well diffusion test [24]. The cultures were grown separately overnight in $50 \mathrm{ml}$ nutrient broth (NB) dispensed in $150 \mathrm{ml}$ Erlenmeyer flasks and incubated as shake cultures at $37^{\circ} \mathrm{C}$. Next, $100 \mu \mathrm{l}$ of each actively grown culture with cell count of approximately $10^{6} \mathrm{cfu} / \mathrm{ml}$ was spread over the nutrient agar plates, in which three wells $(7 \mathrm{~mm})$ were punched for the addition of fungal filtrate and Ag nanoparticle solution. The Ag nanoparticle solutions (50 and $100 \mu \mathrm{g} / \mathrm{ml}$ ) were placed in their respective wells and the plates were incubated for $24 \mathrm{~h}$ at $37^{\circ} \mathrm{C}$, and the antibacterial effectiveness was assessed on the basis of the zones of inhibition around the wells.

\subsection{Determination of the minimum inhibitory concentration (MIC) and minimum bactericidal concentration (MBC) of the biologically synthesized Ag nanoparticles against common food borne pathogens}

The MIC of Ag nanoparticles was determined by using the broth micro dilution method against the common food-borne pathogens, including S. aureus, E. coli and S. typhimurium. About $2 \mathrm{ml}$ of the geometric concentrations of nanoparticles (32, 64, 128, 256, 512, 1024, $2048 \mu \mathrm{g} / \mathrm{ml}$ ) in Mueller Hinton broth (MHB) were used in test tubes $(12 \times 100 \mathrm{~mm})$ and then inoculated separately with each of actively grown cultures with a cell count of approximately $10^{6} \mathrm{cfu} / \mathrm{ml}$. The positive control consisted of inoculated MHB broth and the negative control contained only uninoculated MHB medium. The incubation time and temperature were taken $24 \mathrm{~h}$ and $37^{\circ} \mathrm{C}$. The MIC was determined as the lowest concentration of Ag nanoparticles, which repressed the noticeable development of bacteria after overnight incubation. The MBC was determined by plating the substance of the tubes containing MIC and a higher concentration of biosynthesized Ag nanoparticles on nutrient agar plate and incubated at $37^{\circ} \mathrm{C}$ for $24 \mathrm{~h}$. MBC was defined as the lowest concentration of Ag nanoparticles resulting in the $>99.9 \%$ reduction of the initial inoculums. All analyses were carried out in triplicates.

\subsection{Data analysis}

All the values are expressed as mean \pm standard deviation of three independent experiments with three replicates each. The results were statistically analyzed using ANOVA with the Holm-Šídák method using a sigma plot (Systat Software, San Jose, CA, USA).

\section{Results}

\subsection{Morphological and molecular analysis of the strain GRS-1}

The microscopic examination of the fungal strain isolated from the natural biodiversity showed smooth mycelium with branched conidiophores having ellipsoidal conidiospores and smooth walls in a long chain, which are the typical characteristics of the genus Penicillium [25]. On the basis of the nucleotide homology and phylogenetic analysis of the $18 \mathrm{~S}$ rDNA sequence, the strain GRS-1 was found to be close to P. oxalicum BT (Gen Bank Accession Number: KT189509.1) and hence was named as P. oxalicum GRS-1.

\subsection{Production of the nitrate reductase by P. oxalicum GRS-1 and the biosynthesis of Ag nanoparticles}

The reduction of $\mathrm{Ag}^{+}$to $\mathrm{Ag}^{0}$ was mediated by the bio-molecules present in the cell filtrate of $P$. oxalicum GRS-1, which revealed the nitrate reductase activity of $94.61 \mathrm{IU} / \mathrm{ml}$. The biosynthesis of Ag nanoparticles was visually recognized by the appearance of brown color in the solution containing cell filtrate and $\mathrm{AgNO}_{3}$. The presence of Ag nanoparticles was confirmed by the ultraviolet (UV)visible spectra of the cell filtrate with $\mathrm{AgNO}_{3}$, which demonstrated a strong wide peak between 410 and $450 \mathrm{~nm}$ (surface plasmon resonance band). The power of the SPR band continuously increased from 4 to $96 \mathrm{~h}$ as a function of time of response.

\subsection{Characterization of the Ag nanoparticles}

\subsubsection{X-Ray diffraction analysis}

XRD analysis demonstrated the development of Ag nanoparticles, which was affirmed by various diffraction crests in the XRD investigation, as indicated in Figure 1. Bragg's reflection was clearly depicted and distinctly exhibited in the XRD pattern of the biosynthesized Ag nanoparticles, the peaks were recorded on the basis of face-centered cubic (FCC). The XRD graph exhibited sharp peaks at 9, 11, $21,22,27,32,38$ and 46 positions relating to the diffractions from the planes of Ag with FCC cross sections. The patterns absolutely showed that Ag nanoparticles were synthesized by the reduction of metal ions by $P$. oxalicum GRS-1. The 


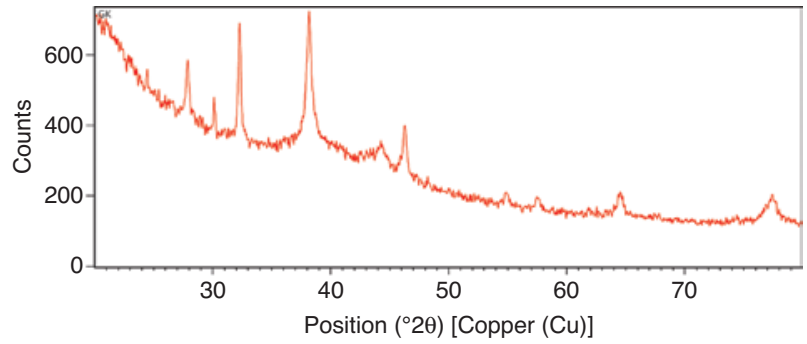

Figure 1: The XRD analysis of the biologically synthesized Ag nanoparticles. sharpening of peaks clearly demonstrated that the particles were in nanoregime. The average size of the nanocrystalites, as estimated from FWHM using the Scherrer's formula, $D=0.94 \lambda / \beta \cos \theta$, was in the range of $19-36 \mathrm{~nm}$.

\subsubsection{FESEM analysis}

The shape of the biosynthesized Ag nanoparticles as determined by FESEM micrographs was spherical and
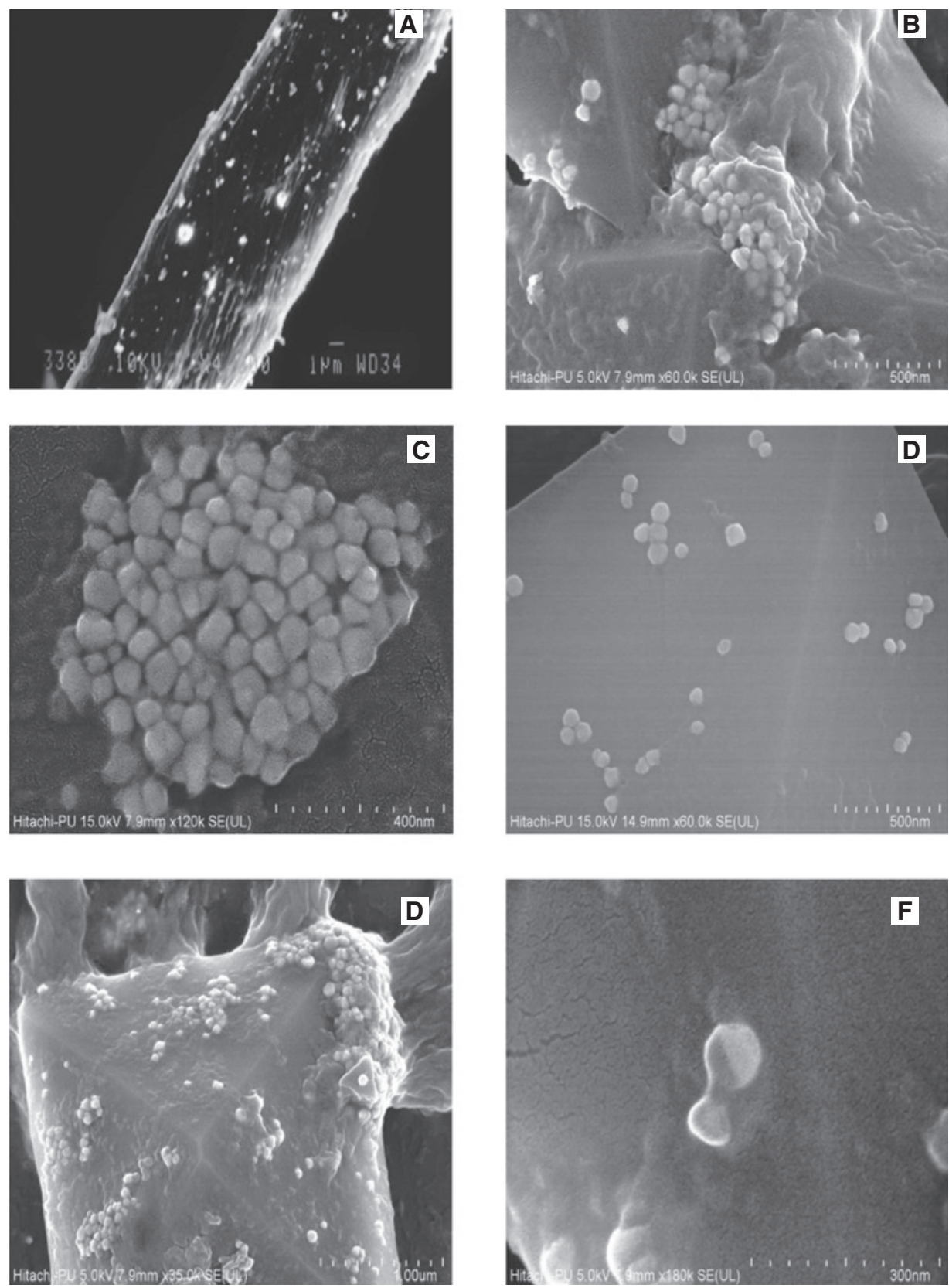

Figure 2: The FESEM images of the biologically synthesized Ag nanoparticles using cellular extract of Penicillium oxalicum GRS-1. (A) Ag nanoparticles attached with fungal mycelium at $1.0 \mu \mathrm{m}$, (B) Ag nanoparticles in cluster at $500 \mathrm{~nm}$, (C) Ag nanoparticles in cluster at $400 \mathrm{~nm}$, (D) Separated Ag nanoparticles at $500 \mathrm{~nm}$, (E) Ag nanoparticles at $1.0 \mu \mathrm{m}$ and (F) Ag nanoparticles at $300 \mathrm{~nm}$. 


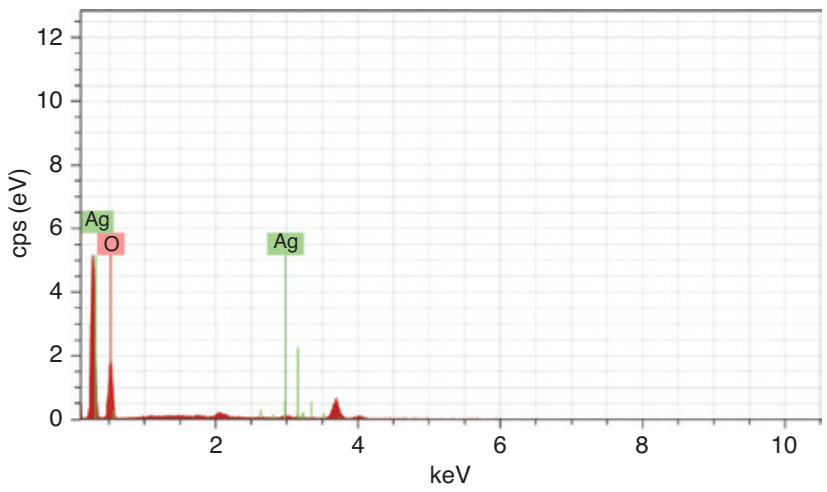

Figure 3: The EDX spectra of the biologically synthesized Ag nanoparticles using cellular extract of Penicillium oxalicum GRS-1.

monodispersed (Figure 2A-E). The elemental profile of the biologically synthesized Ag nanoparticles, as analyzed by EDX graphs, showed the optical absorption peak at $3 \mathrm{KeV}$, which corresponds to metallic Ag and hence confirms the biosynthesis of the Ag nanoparticles (Figure 3).

\subsubsection{TEM analysis}

Nanoparticles of different sizes running from 10 to $100 \mathrm{~nm}$ (Figure 4) were observed as separated and aggregated in TEM analysis. The morphology of the nanoparticles was highly variable and they were not in coordinate contact even within the aggregates, thus demonstrating the stabilization of the nanoparticles by a capping agent.

\subsubsection{FTIR spectroscopy analysis}

The FTIR analysis of the biologically synthesized Ag nanoparticles revealed peaks corresponding to the $\mathrm{N}-\mathrm{H}$ stretch at 3638.59, 3699.59 and $3787.59 \mathrm{~cm}^{-1}$, alkyl C-H stretch at $2854.54 \mathrm{~cm}^{-1}$ and $2924.52 \mathrm{~cm}^{-1}$ as well as the $\mathrm{C}=\mathrm{O}$ stretch of ester at $1742.54 \mathrm{~cm}^{-1}$. The vibrational bands at 1551.54 and $1464 \mathrm{~cm}^{-1}$ corresponded to the N-H stretch and C-N (amines) asymmetric stretch in the amide linkages of the proteins, respectively (Figure 5).

\subsection{Optimization of the biological synthesis of Ag nanoparticles}

\subsubsection{Effect of $\mathrm{pH}$}

$\mathrm{pH}$ is one of the major environmental factor that influences the production of Ag nanoparticles. The Ag nanoparticls
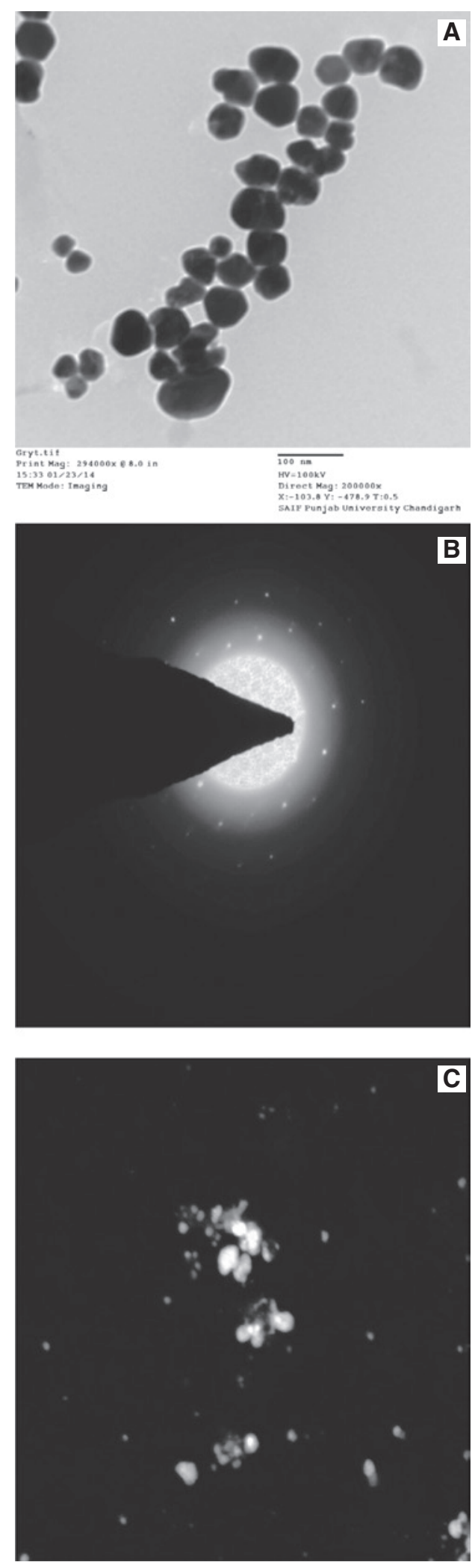

Figure 4: The TEM images of the Ag nanoparticles synthesized using the cellular extract of Penicillium oxalicum GRS-1. (A) TEM image of Ag nanoparticles at a scale of $100 \mathrm{~nm}$. (B) Selected area electron diffraction pattern (SAED) of Ag nanoparticles. (C) High Resolution TEM image of biologically synthesized Ag nanoparticles. 


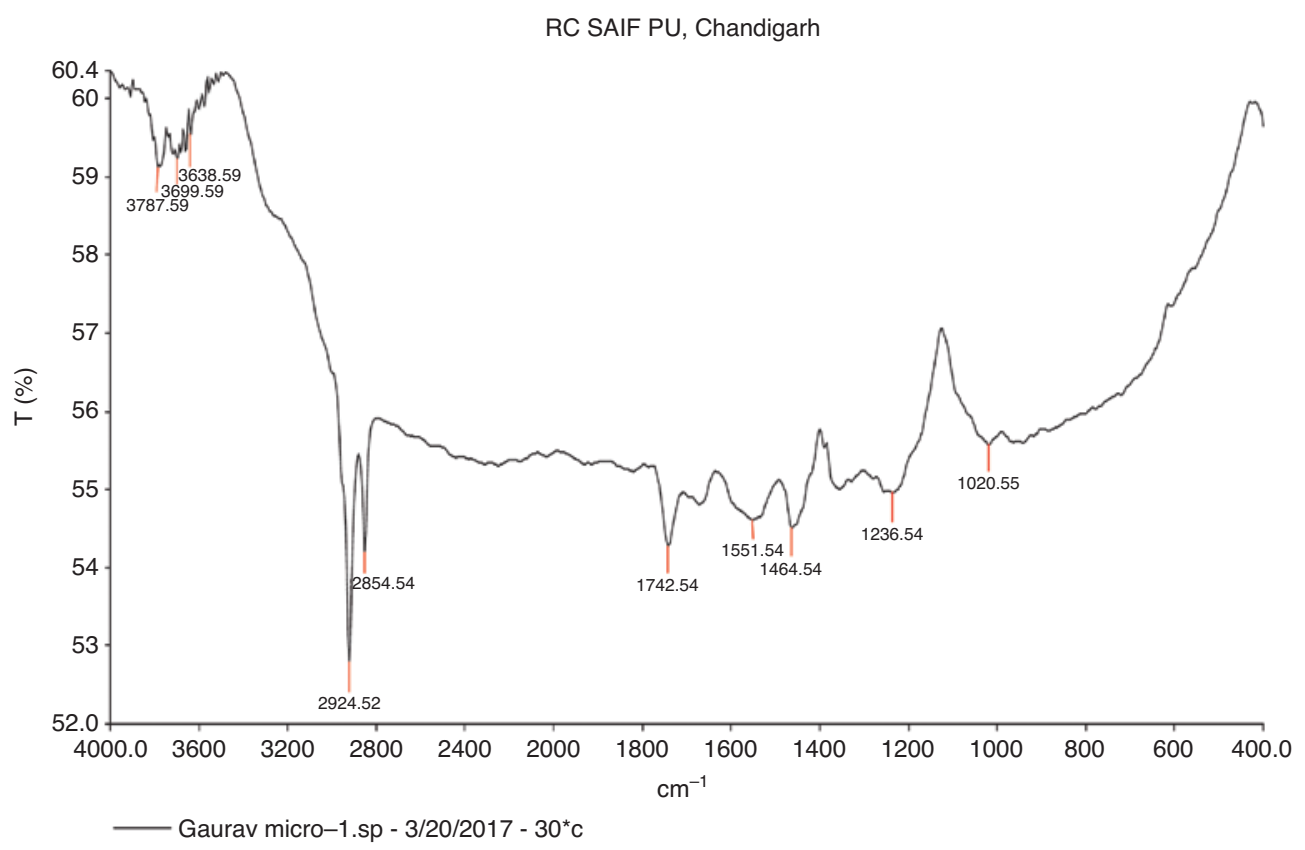

Figure 5: The FTIR spectrum of the Ag nanoparticles synthesized using the cell-free extracts of Penicillium oxalicum GRS-1.

production was very slow in an acidic range where smaller and broader peaks were observed. With the increase in $\mathrm{pH}$ of the solution, the absorbance peaks were found to be narrower and sharper, indicating the spherical and smaller sized production of Ag nanoparticles. At $\mathrm{pH} 7.0$ and 8.0 the peak was found to be highly symmetrical, thus confirming the uniform distribution of nanoparticles (Figure 6A). The maximum peak intensity corresponding to 1.333 was observed at $450 \mathrm{~nm}$ at $\mathrm{pH} 7.0$, indicating the higher concentration of Ag nanoparticles produced in the solution (Table 1).

\subsubsection{Effect of temperature}

Temperature is one of the key controlling factor affecting the formation of Ag nanoparticles. With an increase in temperature from $20^{\circ} \mathrm{C}$ to $60^{\circ} \mathrm{C}$, there was shifting of peak towards a lower wavelength, which revealed a reduction in particle size (Figure 6B). Broader peaks were observed at a low temperature, which indicated the existence of different sizes of Ag nanoparticles. In comparison, the narrower peaks were obtained at a higher temperature, which showed the presence of a narrow range of Ag nanoparticles in the solution. The highest and narrower peak was obtained at $60^{\circ} \mathrm{C}$. The peak intensity was found to be maximum (3.063) at $418 \mathrm{~nm}$, indicating the presence of a large number of Ag nanoparticles in the solution (Table 1). The peak was found to be most symmetrical at $40^{\circ} \mathrm{C}$, which indicated that the biosynthesized Ag nanoparticles were monodispersed in nature.

\subsubsection{Effect of the $\mathrm{AgNo}_{3}$ concentration}

The influence of $\mathrm{AgNO}_{3}$ concentration on the production of Ag nanoparticles was evaluated by varying the concentration of $\mathrm{AgNo}_{3}$ (Figure 6C). There was a gradual increase in the production of $\mathrm{Ag}$ nanoparticles by up to $1.5 \mathrm{~mm} \mathrm{AgNO}_{3}$ concentration. The maximum value of peak intensity corresponding to 2.149 in the presence of $1.5 \mathrm{mM} \mathrm{AgNO}_{3}$ was found to be at $414 \mathrm{~nm}$, which indicated the higher production of Ag nanoparticles (Table 1). With an increase in the $\mathrm{AgNO}_{3}$ concentration, there was distortion in the peak symmetry and the peak became flattened, thus indicating non-uniformity in particle size.

\subsubsection{Effect of the fungal biomass concentration}

With an increase in biomass concentration from 5 to $25 \mathrm{~g}$, more symmetrical, sharp and narrower absorbance peaks were obtained, indicating the small sized and uniform distribution of Ag nanoparticles (Figure 6D). The maximum value of peak intensity corresponding to 1.979 was found to be at $414 \mathrm{~nm}$ with $25 \mathrm{~g}$ biomass (Table 1), thus indicating the highest production of Ag nanoparticles. 

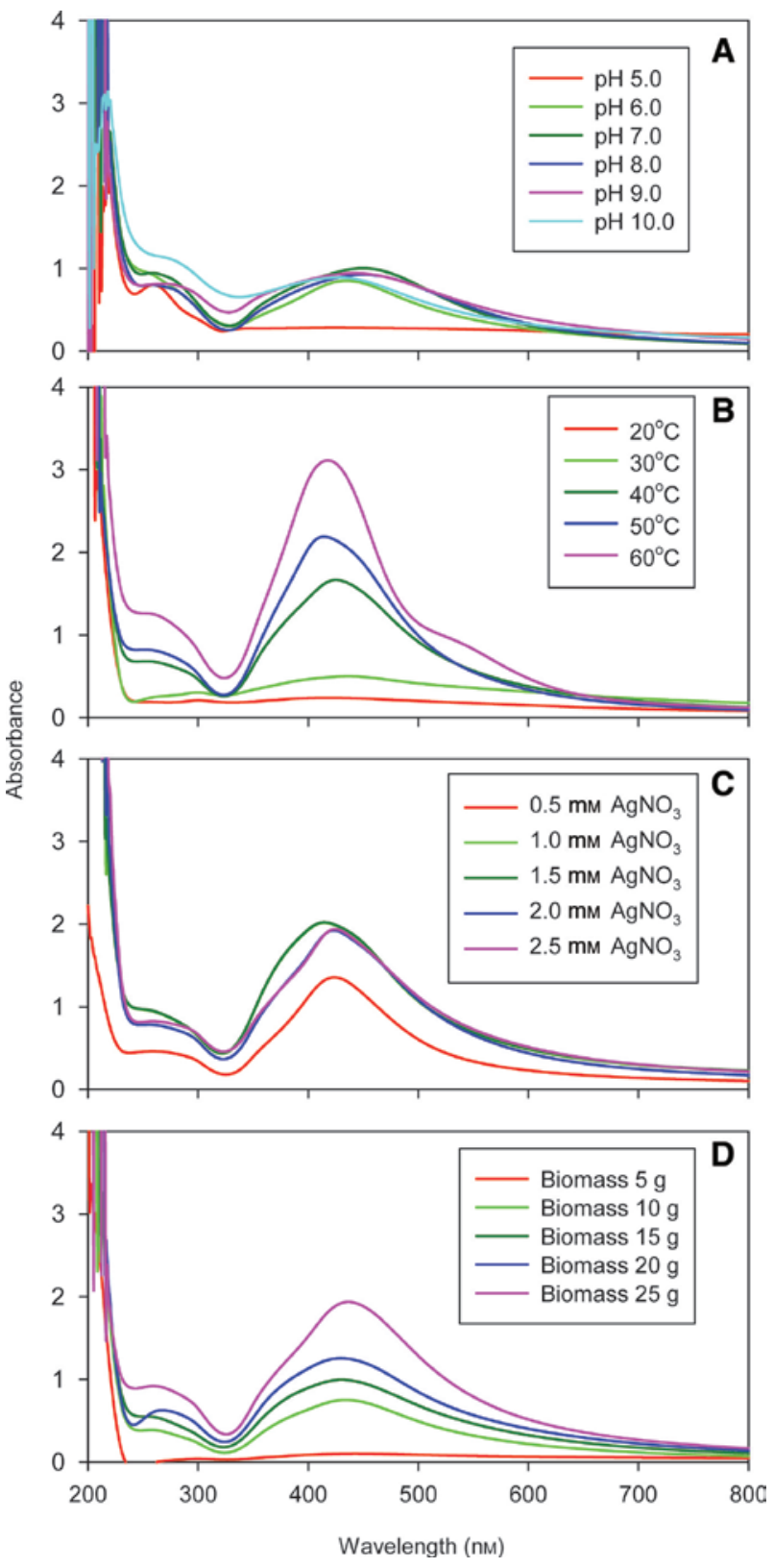

Figure 6: The effects of $\mathrm{pH}(\mathrm{A})$, temperature (B), $\mathrm{AgNO}_{3}$ concentration (C) and fungal biomass concentration (D) on the biosynthesis of $\mathrm{Ag}$ nanoparticles using the cellular extract from Penicillium oxalicum GRS-1.

\subsection{Statistical optimization of $\mathrm{Ag}$ nanoparticle production by response surface methodology (RSM)}

The experimental designs resulting in 20 experimental runs with the examined responses for Ag nanoparticles generation are presented in Table 2. The regression equation was created to investigate the interacting factors by recognizing the critical factors adding to the regression model and determining the optimal values of the most noteworthy independent factors. To choose the right sufficiency of model for Ag nanoparticles production, two different tests viz., sequential model sum of squares and model summary statistics were carried out. Different models, including linear, 2F1, quadratic and cubic, were employed to try to improve the Ag nanoparticles biosynthesis on the premise of their F-value, $\mathrm{p}$-value, determination coefficient $\left(\mathrm{R}^{2}\right)$, standard deviation and PRESS values. Of the considerable number of models examined, the quadratic regression model was observed to be noteworthy. The ANOVA analysis indicated a linear relationship between the significant effects of $\mathrm{pH}, \mathrm{AgNo}_{3}$ concentration and incubation time; the interactions between $\mathrm{pH}$ and $\mathrm{AgNo}_{3}$ concentration, between $\mathrm{AgNo}_{3}$ and incubation time and between $\mathrm{pH}$ and incubation time; the quadratic relationship with $\mathrm{pH} ; \mathrm{AgNo}_{3}$ concentration and incubation time. By applying multiple regression analysis on the trial data, the following secondorder polynomial equation was found to clarify the Ag nanoparticle biosynthesis by just considering the noteworthy terms and is shown in Equation (3).

$$
\begin{aligned}
& \text { Ag nanoparticle yield }=138.20+6.19 \times \mathrm{A}+10.44 \times \mathrm{B} \\
& +12.56 \times \mathrm{C}+10.88 \times \mathrm{A} \times \mathrm{B}-6.12 \times \mathrm{A} \times \mathrm{C}-2.87 \times \mathrm{B} \times \mathrm{C} \\
& -16.77 \times \mathrm{A}^{2}-15.65 \times \mathrm{B}^{2}-10.77 \times \mathrm{C}^{2},
\end{aligned}
$$

where $\mathrm{A}, \mathrm{B}$ and $\mathrm{C}$ are $\mathrm{pH}, \mathrm{AgNo}_{3}$ concentration and incubation time, respectively. The ANOVA for the Ag nanoparticle biosynthesis, as depicted in Table 3, demonstrates the model F-value of 89.30, showing that the model is significant. There is just a $0.01 \%$ possibility that a "Model F-Value" this extensive could happen due to noise. The p-values less than 0.0500 showed the significance of the model terms. The estimation of correlation coefficient $\left(\mathrm{R}^{2}=0.9877\right)$ demonstrated that $98.7 \%$ inconstancy can be revealed by the model. The value signal to noise proportion $(\mathrm{S} / \mathrm{N})$, which is a measure of the satisfactory accuracy is 25.090. A value greater than 4 is desirable in support of the fitness of the model. The coefficient of variation (CV) indicates the degree of precision with which the treatments are compared. Usually, the larger the value of $\mathrm{CV}$, the lower the dependability of the experiment is. In this experiment, a lower value of $\mathrm{CV}$ corresponding to 4.54 indicated a greater reliability of the analysis performed. The thus investigation demonstrated that the form of the model chosen to reveal the relationship between the factors and the response was correct. In this case $\mathrm{A}, \mathrm{B}, \mathrm{C}, \mathrm{AB}, \mathrm{AC}, \mathrm{A}^{2}, \mathrm{~B}^{2}$ and $\mathrm{C}^{2}$ are significant model terms. However, some regression coefficients (i.e. $\mathrm{BC}$ ) were found to be unnecessary, having $\mathrm{p}$-values $>0.05$, thus suggesting their insignificance. However, this was still included in order to improve the model. 
Table 1: The effects of various parameters on the peak intensity of the biosynthesized Ag nanoparticles.

\begin{tabular}{|c|c|c|c|c|c|c|c|}
\hline $\mathrm{pH}$ & Peak intensity & $\begin{array}{r}\text { Temperature } \\
\left({ }^{\circ} \mathrm{C}\right)\end{array}$ & Peak intensity & $\begin{array}{r}\mathrm{AgNO}_{3} \\
\text { concentration }(\mathrm{mm})\end{array}$ & Peak intensity & $\begin{array}{r}\text { Biomass } \\
\text { concentration (g) }\end{array}$ & Peak intensity \\
\hline 5 & $0.229 \pm 0.0501^{\mathrm{a}, \mathrm{b}, \mathrm{c}}$ & 20 & $0.275 \pm 0.0322^{b}$ & 0.5 & $1.236 \pm 0.118$ & 5 & $0.12 \pm 0.0425$ \\
\hline 6 & $0.888 \pm 0.0872^{\mathrm{b}, \mathrm{e}, \mathrm{ll}, \mathrm{l}, \mathrm{m}}$ & 30 & $0.52 \pm 0.0432^{\mathrm{b}}$ & 1.0 & $2.089 \pm 0.3^{\mathrm{b}, \mathrm{d}, \mathrm{f}}$ & 10 & $0.847 \pm 0.0843$ \\
\hline 7 & $1.333 \pm 0.578^{\mathrm{d}, \mathrm{e}, \mathrm{f}, \mathrm{g}}$ & 40 & $1.847 \pm 0.171^{\mathrm{a}}$ & 1.5 & $2.149 \pm 0.26^{\mathrm{a}, \mathrm{c}, \mathrm{f}}$ & 15 & $1.102 \pm 0.108^{\mathrm{a}}$ \\
\hline 8 & $1.003 \pm 0.0887^{\mathrm{g}, \mathrm{h}, \mathrm{l}, \mathrm{k}}$ & 50 & $2.146 \pm 0.132^{\mathrm{a}}$ & 2.0 & $1.84 \pm 0.097^{\mathrm{a}, \mathrm{b}, \mathrm{e}}$ & 20 & $1.288 \pm 0.198^{\mathrm{a}}$ \\
\hline 9 & $0.936 \pm 0.044^{\mathrm{a}, \mathrm{f}, \mathrm{j}, \mathrm{k}, \mathrm{l}}$ & 60 & $3.063 \pm 0.222$ & 2.5 & $1.922 \pm 0.095^{\mathrm{c}, \mathrm{d}, \mathrm{e}}$ & 25 & $1.979 \pm 0.0388$ \\
\hline 10 & $0.854 \pm 0.0832^{\mathrm{c}, \mathrm{d}, \mathrm{h}, \mathrm{j}, \mathrm{m}}$ & & & & & & \\
\hline
\end{tabular}

${ }^{a-m}$ Values with the same letter in the same column do not differ significantly based on the Holm-Šídák test $(p>0.001)$. All the other values differ significantly from each one another with $p<0.001$.

Table 2: The central composite design matrix with the experimental values of the Ag nanoparticles produced with Penicillium oxalicum GRS-1.

\begin{tabular}{lrrrr}
\hline Runs & pH & $\begin{array}{r}\text { AgNO }_{3} \\
\text { concentration (mM) }\end{array}$ & $\begin{array}{r}\text { Incubation } \\
\text { time (h) }\end{array}$ & $\begin{array}{r}\text { Ag nanoparticles } \\
(\mathbf{p p m})\end{array}$ \\
\hline 1 & 7.00 & 1.50 & 72.00 & 136 \\
2 & 7.00 & 1.50 & 72.00 & 139 \\
3 & 8.00 & 2.00 & 96.00 & 131 \\
4 & 6.00 & 1.00 & 48.00 & 69 \\
5 & 8.00 & 1.00 & 48.00 & 74 \\
6 & 7.00 & 1.50 & 120.00 & 119 \\
7 & 7.00 & 1.50 & 72.00 & 138 \\
8 & 7.00 & 0.50 & 72.00 & 55 \\
9 & 7.00 & 1.50 & 72.00 & 135 \\
10 & 8.00 & 2.00 & 48.00 & 125 \\
11 & 6.00 & 2.00 & 48.00 & 78 \\
12 & 9.00 & 1.50 & 72.00 & 79 \\
13 & 6.00 & 2.00 & 96.00 & 107 \\
14 & 8.00 & 1.00 & 96.00 & 90 \\
15 & 6.00 & 1.00 & 96.00 & 111 \\
16 & 7.00 & 1.50 & 72.00 & 138 \\
17 & 7.00 & 2.50 & 72.00 & 90 \\
18 & 7.00 & 1.50 & 24.00 & 65 \\
19 & 7.00 & 1.50 & 72.00 & 137 \\
20 & 5.00 & 1.50 & 72.00 & 57 \\
\hline
\end{tabular}

\subsubsection{Interactions among the factors}

Student's t-test was used to analyze the knowledge of the error mean square that is crucial in examining the significance of the predicted coefficient of the regression equation. The greater the magnitude of the $t$ value and the smaller the $p$ value, the more significant is the corresponding coefficient. The coefficient estimates and t values in the quadratic model, as depicted in Table 3 revealed that factors A, B and C had direct effects on Ag nanoparticle production with incubation time, revealing the maximal effect. The inter communication between the factors AC and $\mathrm{BC}$ revealed the opposing effects on nanoparticle production, whereas the interactions between $\mathrm{AB}$ had positive effects on $\mathrm{Ag}$ nanoparticle production. The 3D surface graphs (Figure 7) revealed the interconnection between the two factors for the optimization of conditions for the Ag nanoparticle production. From the plots, we can easily see the interactions between two factors and locate the optimum levels. Each curve exhibits an immense number of combinations of two test variables with the other variables sustained at the constant level. The surface graph, which was accomplished as a function of $\mathrm{pH}$ versus

Table 3: The ANOVA results for the response surface quadratic model employed for the biosynthesis of the Ag nanoparticles.

\begin{tabular}{lrrrrr}
\hline Source & Sum of squares & Coefficient estimate & t-test & F value & p-Value \\
\hline Model & 17789.21 & 138.2045 & 73.51 & 89.30 & $<0.0001$ \\
A-pH & 612.56 & 6.1875 & 5.24 & 27.68 & 0.0004 \\
B-AgNO $_{3}$ & 1743.06 & 10.4375 & 8.845 & 78.75 & $<0.0001$ \\
C-incubation time & 2525.06 & 12.5625 & 10.646 & 114.08 & $<0.0001$ \\
AB & 946.13 & 10.875 & 6.55 & 42.75 & $<0.0001$ \\
AC & 300.13 & -6.125 & -3.689 & 13.56 & 0.0042 \\
BC & 66.13 & -2.875 & -1.73 & 2.99 & 0.1146 \\
A $^{2}$ & 7073.30 & -16.7727 & -17.84 & 319.57 & $<0.0001$ \\
B $^{2}$ & 6156.26 & -15.6477 & -16.64 & 278.14 & $<0.0001$ \\
C $^{2}$ & 2917.87 & -10.7727 & -11.46 & 131.83 & $<0.0001$ \\
Residual & 221.34 & 138.2045 & & & \\
\hline
\end{tabular}





Figure 7: The 3D surface graphs representing the Ag nanoparticle yields from the crude cellular extracts of Penicillium oxalicum GRS-1 as affected by $\mathrm{pH}$ and $\mathrm{AgNO}_{3}$ concentration ( $\mathrm{A}$ ), $\mathrm{pH}$ and incubation time (B), incubation time and $\mathrm{AgNO}_{3}$ concentration (C) keeping the other variables at 0 coded values.

$\mathrm{AgNo}_{3}$ concentration, showed that $\mathrm{Ag}$ nanoparticle production was enhanced with the increase of both $\mathrm{pH}$ and $\mathrm{AgNo}_{3}$; however, at high concentration, the nanoparticle production decreased. The maximum production of $\mathrm{Ag}$ nanoparticles corresponding to $141.563 \mathrm{ppm}$ was obtained in the optimized medium, where the $\mathrm{pH}$ and $\mathrm{AgNo}_{3}$ concentration were 7.33 and $1.72 \mathrm{~mm}$, respectively (Figure $7 \mathrm{~A}$ ) while incubation time was held at the 0 code level. The surface graph obtained as a function of $\mathrm{pH}$ of reaction mixture versus incubation time showed that the nanoparticle production increased with the increase in $\mathrm{pH}$ and incubation time. The maximum production of Ag nanoparticles corresponding to $141.974 \mathrm{ppm}$ occurred at a $\mathrm{pH} 7.09$ and $85.50 \mathrm{~h}$ of incubation time while the $\mathrm{AgNo}_{3}$ concentration was held at the 0 code level (Figure 7B). Figure $7 \mathrm{C}$ shows the effect of the $\mathrm{AgNO}_{3}$ concentration and incubation time on the $\mathrm{Ag}$ nanoparticle production. As can be seen, an increase in the concentration of $\mathrm{AgNo}_{3}$ and duration of incubation time promoted the Ag nanoparticle production. However, the Ag nanoparticle production decreased at a high concentration of $\mathrm{AgNo}_{3}(1.64 \mathrm{~mm})$ and incubation time duration of $85.04 \mathrm{~h}$. The maximum production of the Ag nanoparticles corresponding to $143.108 \mathrm{ppm}$ was obtained at $1.64 \mathrm{mM}$ of $\mathrm{AgNo}_{3}$ and the incubation time of $85.04 \mathrm{~h}$ while the $\mathrm{pH}$ value was held at the 0 code level.

\subsubsection{Model validation}

In order to determine the precision of the statistical experimental model of RSM, efforts were made to develop the process parameters of reaction mixture for augmenting the Ag nanoparticle production using different variables. The numerical optimization for Ag nanoparticle production was attempted with Design expert using A ( $\mathrm{pH}, 7.2)$, $\mathrm{B}\left(\mathrm{AgNo}_{3}\right.$ concentration, $\left.1.975 \mathrm{~mm}\right)$ and $\mathrm{C}$ (incubation time, $85.775 \mathrm{~h}$ ), incubated at $40^{\circ} \mathrm{C}$ in shaking condition at $150 \mathrm{rpm}$. This procedure predicted the yield corresponding to $139.069 \mathrm{ppm}$. To substantiate the optimum concentrations, an experiment with the above particularized conditions was carried out and the result corresponded to $136 \mathrm{ppm}$, which was found to be very close to the anticipated value. This high degree of precision affirmed the reliability of the model with only an insignificant error due to the negligible deflection in experimental conditions. The statistical interpretation of environmental conditions thus intensifies the production of Ag nanoparticles to a considerable amount.

\subsection{In vitro assessment of the anti-bacterial activity of the Ag nanoparticles}

The biologically synthesized Ag nanoparticles at a concentration of $100 \mu \mathrm{g} / \mathrm{ml}$ showed very strong inhibitory 
Table 4: The inhibitory effect of the Ag nanoparticles against various pathogens achieved though the well diffusion test method.

\begin{tabular}{|c|c|c|c|}
\hline Pathogen & $\begin{array}{l}\text { Zone of } \\
\text { inhibition } \\
\text { (fungal cell } \\
\text { filtrate) }\end{array}$ & $\begin{array}{l}\text { Zone of } \\
\text { inhibition } \\
(50 \mu \mathrm{g} / \mathrm{ml} \\
\text { of AgNPs) }\end{array}$ & $\begin{array}{l}\text { Zone of } \\
\text { inhibition } \\
(100 \mu \mathrm{g} / \mathrm{ml} \\
\text { of AgNPs) }\end{array}$ \\
\hline Staphylococcus aureus & - & $10 \mathrm{~mm}$ & $14 \mathrm{~mm}$ \\
\hline Salmonella typhimurium & - & $10 \mathrm{~mm}$ & $14 \mathrm{~mm}$ \\
\hline Escherichia coli & - & $12 \mathrm{~mm}$ & $15 \mathrm{~mm}$ \\
\hline
\end{tabular}

effect against common food-borne pathogens, including S. aureus, E. coli and S. typhimurium revealing 14, 15 and $14 \mathrm{~mm}$ zones of inhibition, respectively (Table 4).

\subsubsection{Determination of the MIC and MBC of the biologically synthesized Ag nanoparticles}

After $24 \mathrm{~h}$ of incubation at $37^{\circ} \mathrm{C}$, turbidity was seen in the test tubes containing 8 and $16 \mu \mathrm{g} / \mathrm{ml} \mathrm{Ag} \mathrm{nanoparticles,}$ indicating the growth of $S$. aureus and S. typhimurium, while in the case of $E$. coli, turbidity was observed in the test tube containing $8 \mu \mathrm{g} / \mathrm{ml}$ of $\mathrm{Ag}$ nanoparticles only. Further, no turbidity was observed in the test tubes containing $32-256 \mu \mathrm{g} / \mathrm{ml}$ of Ag nanoparticles in the cases of $S$. aureus and S. typhimurium and 16-256 $\mu \mathrm{g} / \mathrm{ml}$ of Ag nanoparticles in the case of $E$. coli, thus indicating the inhibition of bacterial growth.

To confirm the growth, the suspension from all the test tubes, including negative and positive controls, was inoculated in nutrient agar plates and incubated for $24 \mathrm{~h}$. Bacterial growth was observed in the area marked positive control, 8 and $16 \mu \mathrm{g} / \mathrm{ml}$ of $\mathrm{Ag}$ nanoparticles in case of $S$. aureus and $S$. typhimurium, whereas in the case of $E$. coli, bacterial growth was observed in the area marked positive control and $8 \mu \mathrm{g} / \mathrm{ml}$ of Ag nanoparticles. Further, no growth was observed in the area marked

Table 5: The minimum bactericidal concentration of the $\mathrm{Ag}$ nanoparticles after $24 \mathrm{~h}$ on agar plates.

\begin{tabular}{|c|c|c|c|c|c|c|c|c|}
\hline \multirow[t]{2}{*}{ Pathogen } & \multirow{2}{*}{$\begin{array}{l}\text { Negative } \\
\text { control }\end{array}$} & \multirow{2}{*}{$\begin{array}{l}\text { Positive } \\
\text { control }\end{array}$} & \multicolumn{6}{|c|}{ AgNOPs $(\mu \mathrm{g} / \mathrm{ml})$} \\
\hline & & & 08 & 16 & 32 & 64 & 128 & 256 \\
\hline $\begin{array}{l}\text { Salmonella } \\
\text { typhimurium }\end{array}$ & - & + & + & + & - & - & - & - \\
\hline $\begin{array}{l}\text { Staphylococcus } \\
\text { aureus }\end{array}$ & - & + & + & + & - & - & - & - \\
\hline Escherichia coli & - & + & + & - & - & - & - & - \\
\hline
\end{tabular}

$32-256 \mu \mathrm{g} / \mathrm{ml}$ of Ag nanoparticles in the cases of $S$. aureus and S. typhimurium and $16-256 \mu \mathrm{g} / \mathrm{ml}$ of Ag nanoparticles in the case of $E$. coli. The MBC of Ag nanoparticles against S. aureus, and S. typhimurium was found to be $32 \mu \mathrm{g} / \mathrm{ml}$ and that for $E$. coli was $16 \mu \mathrm{g} / \mathrm{ml}$, indicating that Ag nanoparticles have both bacteriostatic and bactericidal activities (Table 5).

\section{Discussion}

Nanoparticles play a significant role in various fields, including environment, health care, energy, agriculture, and so on. Large numbers of microbes have been found to be capable of biosynthesizing nanoparticles as their cellular extracts act as both reducing as well as capping agents. The nitrate reductase-mediated biosynthesis of $\mathrm{Ag}$ nanoparticles is the most acknowledged process, and during this catalysis, nitrate is reduced to nitrite and an electron is transported to the approaching Ag ions. The direct evidence was reported by Anil Kumar et al. [14], who straightforwardly utilized the purified nitrate reductase from the Fusarium oxysporum for the production of the $\mathrm{Ag}$ nanoparticles. In the present report, a natural isolate of $P$. oxalicum GRS-1 was utilized for the production of Ag nanoparticles owing to the presence of nitrate reductase in its cellular extracts. The reddish brown shade of the solution was due to the SPR of the Ag nanoparticles formed [26]. These results are similar to the findings of Wiley et al. [27], who revealed that the aggregate oscillation of conduction electrons inside metal particles facilitated the diffusion and assimilation of light at a specific frequency, giving them shading on account of silver and gold. The UV-Vis spectra of the cell filtrate with $\mathrm{AgNO}_{3}$ demonstrated a solid wide crest between 420 and $460 \mathrm{~nm}$ (SPR band), which were particular for Ag nanoparticles. These results are consistent with the reports of Verma et al. [28], who revealed that the Ag nanoparticles can be biosynthesized extracellularly using Aspergillus clavatus as the fungal system.

The characterization of the Ag nanoparticles was done by using different techniques like XRD analysis, FTIR, SEM and TEM. The development and nature of the biosynthesized nanoparticles were checked by XRD patterns [29]. The XRD graphs of the biosynthesized Ag nanoparticles exhibited sharp peaks at the 9, 11, 21, 22, 27, 32, 38 and 46 positions corresponding to the diffraction from the planes of Ag with the FCC lattice. The patterns indicated that the Ag nanoparticles were formed through the reduction of metal ions by cellular extract obtained from 
P. oxalicum GRS-1. The sharpening of peaks clearly indicate that the particles are in nanorange.

FESEM analysis revealed that the biosynthesized Ag nanoparticles are even shaped and spherical in nature. These results strongly confirm the idea that the cellular extract obtained from $P$. oxalicum GRS-1 might act as a reducing and capping agents in the biosynthesis of $\mathrm{Ag}$ nanoparticles [30]. The reduction of $\mathrm{Ag}$ ions into Ag nanoparticles is additionally confirmed by EDX analysis, which revealed an optical absorption peak at $3 \mathrm{Kev}$ corresponding to metallic Ag [31].

Meanwhile, TEM results revealed further details about the morphology and size of the biologically synthesized $\mathrm{Ag}$ nanoparticles and the same were found to be in the size range of 10-40 nm. Further, the TEM analysis of the biosynthesized Ag nanoparticles confirmed the presence of capping proteins around the Ag nanoparticles [32]. The absorption peak obtained at $280 \mathrm{~nm}$ confirmed the presence of aromatic amino acids (tyrosine and tryptophan) residues of proteins, which act as capping agent around the Ag nanoparticles. The Ag nanoparticles were crystalline in nature, as can be seen from the chosen region diffraction design recorded from one of the nanoparticles in the cluster [31].

FTIR was employed for the detection of possible functional groups within the capping proteins associated with the nanoparticles, which may be responsible for the reduction and stabilization of the Ag nanoparticles. The appearance of peaks at 1551.54 and $1464 \mathrm{~cm}^{-1}$ represented the amide 1 and amide 3 bands in the FTIR spectra which revealed the presence of protein around the Ag nanoparticles. The vibrational bands at 1551.54 and $1464 \mathrm{~cm}^{-1}$ corresponding to the N-H stretch and C-N (amines) asymmetric stretch, respectively, were also found in the amide linkages of the proteins (Figure 5). These functional groups play important roles in maintaining stability and capping of Ag nanoparticles, as reported in many studies [30, 33]. Amide 1 and amide 3 spectral bands have been found to be most sensitive to the variation in the secondary structure folding. Overall, the results affirm that the capping protein stabilizes the metallic nanoparticle and inhibits the agglomeration in the medium. This investigation confirms that the production and stabilization of the $\mathrm{Ag}$ nanoparticles in the aqueous medium can be achieved by utilizing biological molecules [31].

The biosynthesis of the Ag nanoparticles by cellular extracts obtained from the mycelia of $P$. oxalicum GRS-1 was optimized by standardizing the effects of $\mathrm{pH}$, temperature, $\mathrm{AgNO}_{3}$ concentration and fungal biomass concentration. In case of the effect of $\mathrm{pH}$ study, there was no nanoparticle formation in the acidic range but there was gradual increase in nanoparticle production with an increase in $\mathrm{pH}$. The production of nanoparticles in the alkaline region shows that the enzyme nitrate reductase was active under the alkaline environment [34]. At pH 8.0, the peak was found to be most symmetrical, indicating the uniform distribution of nanoparticles. At $\mathrm{pH} 7.0$ and 8.0, the nanoparticle production was most symmetrical. Furthermore, nanoparticle production peak became increasingly symmetrical with an increase in $\mathrm{pH}$, which can be explained by the fact that the $\mathrm{OH}^{-}$groups plays a crucial role in the stabilization of $\mathrm{Ag}$ nanoparticles and that more nucleation regions are formed due to the availability of $\mathrm{OH}^{-}$, which can prevent the aggregation and assist in maintaining the symmetry with small-sized Ag nanoparticles [35, 36].

With an increase in temperature of the nanoparticle biosynthesis, there was a shifting of peak towards the lower wavelength, which means that the increase in temperature resulted in reduced particle size [37]. This can be probably explained by the fact that, with the increase in temperature, there was also an increase in nucleation, which occurred at various places. The increase in temperature also affects the rate at which the nanoparticles were produced. In this report, the value of peak intensity (3.115) was found to be maximum at $418 \mathrm{~nm}$, thus demonstrating that the yield of the Ag nanoparticles in the current study is higher than that in previous reports. The presence of a band at above $260 \mathrm{~nm}$ was attributed to the electronic excitation in tryptophan and the tyrosine residues in protein, which indicated the presence of protein molecules in colloidal solution [38].

In terms of the influence of the $\mathrm{AgNo}_{3}$ concentration, the maximum biosynthesis of Ag nanoparticles was achieved at the $\mathrm{AgNO}_{3}$ concentration of $1.5 \mathrm{~mm}$. At lower concentrations of $\mathrm{AgNO}_{3}$, the availability of substrate for the enzyme was insufficient, which showed a decrease in the production of Ag nanoparticles. At higher concentrations of $\mathrm{AgNO}_{3}$, the peak symmetry was disturbed, and the peak becomes flattened, indicating that the particles of non-uniform sizes were formed. Such results are in accordance with that of Anil Kumar et al. [14], who revealed the effect of $\mathrm{AgNO}_{3}$ concentration on the biosynthesis of the Ag nanoparticles in E. coli.

One of the important factors responsible for the biosynthesis of the Ag nanoparticles is organism's enzymes. In the present study, we used the crude cellular extracts obtained from fungal biomass for the biosynthesis of $\mathrm{Ag}$ nanoparticles due to the ease in downstream processing of nanoparticles. With increase in biomass concentration (5-25 g), more symmetrical, sharper and narrower absorbance peaks were obtained, indicating the presence 
of the spherical, small-sized and uniform distribution of the Ag nanoparticles [39, 40]. Further, the highest peak intensity corresponding to 1.979 was found to be at $414 \mathrm{~nm}$ with $25 \mathrm{~g}$ biomass, indicating the highest production of Ag nanoparticles. The pattern of increased Ag nanoparticle production with rise in biomass concentration may be attributed to the release of more nitrate reductase from mycelium in the supernatant in the latter (data not shown).

The process of $P$. oxalicum GRS-1 mediating the biological synthesis of the Ag nanoparticles was influenced by various environmental factors, as observed in the study, which employed the one variable at a time approach. The effects of changes in various environmental conditions, including $\mathrm{pH}$, temperature and incubation time, were also evaluated by employing statistical modeling by RSM, which is an empirical modeling technique that is used to evaluate the relationship between a set of controllable experimental factors and observed results [41]. A second-order model like central composite design (CCD) is widely used in RSM because it can take on a wide variety of functional forms, and such flexibility allows it to predict the true response surface more closely. This approach has already been successfully employed to maximize the productivities of various enzymes [42-48]. The major environmental factors that affect the production of $\mathrm{Ag}$ nanoparticles are $\mathrm{pH}$ and temperature. The main goal of RSM is to optimize the various environmental conditions to bring about the increased production of the metal nanoparticles. According to our report, the maximum Ag nanoparticle production amounting to $136 \mathrm{ppm}$ was achieved when the crude cellular extracts of $P$. oxalicum GRS-1 were incubated at $\mathrm{pH}$ 7.2, $\mathrm{AgNo}_{3}$ concentration of $1.975 \mathrm{~mm}$ and incubation time of $85.775 \mathrm{~h}$. This report demonstrated a higher production of Ag nanoparticles than the previously reported results $[11,13,23,30]$.

The antimicrobial efficacy of the biosynthesized Ag nanoparticles in terms of MIC and MBC has been reported in many studies [49-53]. The nanoparticles preferably attack the respiratory chain, cell division and finally lead to cell death. The Ag nanoparticles interact with the sulfur containing membrane proteins of the bacteria as well as with the phosphorous containing compounds like DNA. The antimicrobial action of the Ag nanoparticles on gram negative bacteria was based on the concentration of Ag nanoparticles and was closely associated with the arrangement of pits in the cell wall of bacteria [54]. Ag has a solid antimicrobial potential, which has been used since the ancient times. However, with the advancement in the field of antibiotics, the therapeutic applications of $\mathrm{Ag}$ as antimicrobial were reduced $[55,56]$. The antimicrobial impact of Ag can be expanded by controlling their size at the nano level. Due to the rapid progress in the optimization process, Ag nanoparticles have emerged as potential antimicrobial agents due to their high surface area to volume ratio and unique physiochemical properties [20]. Ag nanoparticles with sizes ranging from 10 to $100 \mathrm{~nm}$ have shown very effective antimicrobial behaviors against both gram-positive and gram-negative bacteria $[57,58]$. Ag nanoparticles biologically synthesized from $P$. oxalicum GRS-1 have also been found to be highly effective against common food-borne pathogens, including S. aureus, E. coli and S. typhimurium with MBC values of 32, 16 and $32 \mu \mathrm{g} / \mathrm{ml}$, respectively.

\section{Conclusion}

Green synthesis provides an eco-friendly, cost-effective and efficient approach for the production of $\mathrm{Ag}$ nanoparticles, which could act as excellent antimicrobial agents against pathogenic microbes. The present study has isolated a strain of $P$. oxalicum GRS-1 from soil, which showed capability of reducing Ag ions into Ag nanoparticles extracellularly with sizes ranging from 10 to $40 \mathrm{~nm}$. The yield of Ag nanoparticles, as evident from the peak intensity, was found to be higher than the previous reports, thus imparting novelty in the study. The biosynthesized Ag nanoparticles were found to be effective against common food-borne pathogens, including S. aureus, E. coli and S. typhimurium with MBC values of 32, 16 and $32 \mu \mathrm{g} / \mathrm{ml}$, respectively. Thus, the strain is a potential candidate for developing a green technology for the commercial biosynthesis of $\mathrm{Ag}$ nanoparticles. The utilization of such biosynthesized nanoparticles in bactericidal applications makes this approach possibly impressive for the large-scale biosynthesis of nanomaterials.

Acknowledgments: The financial assistance provided by the Indian Council of Medical Research (ICMR), India in the form of a Research Fellowship to Mr. Gaurav Kumar is highly acknowledged.

Conflict of interest statement: The authors declare that they have no conflict of interest. 


\section{References}

[1] Uskokovic V. Curr. Nanosci. 2008, 4, 119-129.

[2] Mansoori GA. In Principles of Nanotechnology - Molecular Based Study of Condensed Matter in Small Systems, World Scientific Pub. Co.: Hackensack. N.J., USA, 2005.

[3] Mansoori GA, George TF, Zhang G, Assoufid L. In Molecular Building Blocks for Nanotechnology, Springer: New York, 2007.

[4] Iravani S, Korbekandi H, Mirmohammadi SV, Zolfaghari B. Res. Pharm. Sci. 2014, 9, 385-406.

[5] Ingale AG, Chaudhari AN. J. Nanomed. Nanotechol. 2013, 4, 1-7.

[6] Bhainsa KC, D’Souza SF. Colloids Surf. B. Biointerfaces. 2006, 47, 160-164.

[7] Gade AK, Bonde P, Ingle AP, Marcato PD, Durán N, Rai MK. J. Biobased. Mater. Bioenerg. 2008, 2, 243-247.

[8] Jain N, Bhargava A, Majumdar S, Tarafdar JC, Panwar J. Nanoscale. 2011, 3, 635-641.

[9] Kathiresan K, Manivannan S, Nabeel MA, Dhivya B. Colloids Surf. B. Biointerfaces. 2009, 71, 133-137.

[10] Tran QH, Nguyen VQ, Le AT. Adv. Nat. Sci: Nanosci. Nanotechnol. 2013, 4, 1-20.

[11] Kalimuthu K, Babu RS, Venkataraman D, Bilal M, Gurunathan S. Colloids Surf. B. Biointerfaces. 2008, 65, 150-153.

[12] Kalishwaralal K, Deepak V, Ramkumarpandian S, Nellaiah H, Sangiliyandi G. Mater. Lett. 2008, 62, 4411-4413.

[13] Gholami-Shabani M, Akbarzadeh A, Norouzian D, Amini A, Gholami-Shabani Z. Appl. Biochem. Biotechnol. 2014, 172, 4084-4098.

[14] Anil Kumar S, Abyaneh MK, Gosavi SW, Kulkarni SK, Pasricha R. Biotechnol. Lett. 2007, 29, 439-445.

[15] Gong P, Li H, He X, Wang K, Hu J. Nanotechnol. 2007, 18, 604-611.

[16] Rai M, Yadav A, Gade A. Biotechnol. Adv. 2009, 27, 76-83.

[17] Seil JT, Webster TJ. Int. J. Nanomed. 2012, 7, 2767-2781.

[18] Chernousova S, Epple M. Angew. Chem. Int. Ed. Engl. 2013, 52, 1636-1653.

[19] Krishnakumar S, Divakaran S, Shankar GU, Williams PG, Sasikumar M. J. Chem. Pharm. Res. 2015, 7, 62-67.

[20] Siddiqui MN, Redhwi HH, Achilias DS, Kosmidou E, Kosmidou E, Ioannidou MD. J. Polym. Environ. 2018, 26, 423-433.

[21] AbdelRahim K, Mahmoud SY, Ali AM, Almaary KS, Mustafa AEZMA, Husseiny SM. Saudi. J. Biol. Sci. 2017, 24, 208-216.

[22] Gilliam MB, Sherman MP, Griscavage JM, Ignarro LJ. Anal. Biochem. 1993, 212, 359-365.

[23] Jyoti K, Baunthiyal M, Singh A. J. Radiat. Res. Appl. Sci. 2016, 9 , 217-227.

[24] Deans SG, Ritchie G. Int. J. Food. Microbiol. 1987, 5, 165-218.

[25] Yang L, Xie J, Jiang D, Fu Y, Li G, Li F. World J. Microbiol. Biotechnol. 2008, 24, 909-915.

[26] Kannan N, Mukunthan KS, Balaji S. Colloids Surf. B. Biointerfaces. 2011, 86, 378-383.

[27] Wiley BJ, Im SH, Li ZY, McLellan J, Siekkinen A, Xia Y. J. Phys. Chem. B. 2006, 110, 15666-15675.

[28] Verma VC, Kharwar RN, Gange AC. Nanomed. 2010, 5, 33-40.

[29] Bykkam S, Ahmadipou M, Narisngam S, Kalagadda VR, Chidurala SC. Adv. Nanopart. 2015, 4, 1-10.
[30] Anandalakshmi K, Venugobal J, Ramasamy V. Appl. Nanosci. 2016, 6, 399-408.

[31] Banu A, Rathod V. Int. J. Biomed. \& Adv. Res. 2011, 2, 148-158.

[32] Devaraj P, Kumari P, Aarti C, Renganathan A. J. Nanotechnol. 2013, Article ID 598328, 5 pages, doi:10.1155/2013/598328.

[33] Mukherjee P, Ahmad A, Mandal D, Senapati S, Sainkar SR. Nano. Lett. 2001, 1, 515-519.

[34] Chow F, Capociama FV, Faria R, Oliveira MC. Braz. J. Bot. 2007, 30, 123-129.

[35] Reddy NJ, Vali DN, Rani M, Rani SS. Mater. Sci. Eng. C. 2014, 34, 115-122.

[36] Gomathi M, Rajkumar PV, Prakasam A, Ravichandran K. Res. Efficient Technol. 2017, 3, 280-284.

[37] Patra JK, Baek KH. J. Nanomat. 2014, 2014, 1-12.

[38] Mohammed F, Balaji A, Kalaichelvan K, Venkatesan R. Colloids Surf. B: Biointerfaces. 2009, 74, 123-126.

[39] Soni N, Prakash S. Am. J. Nanotechnol. 2011, 2, 112-121.

[40] Xue B, He D, Gao S, Wang D, Yokoyama K. Int. J. Nanomed. 2016, 11, 1899-1906.

[41] Kumar S, Sharma HK, Sarkar BC. Food Sci. Biotechnol. 2011, 20, 1289-1298.

[42] Abdeshahian P, Samat N, Hamid AA, Yusoff WMW. J. Ind. Microbiol. Biotechnol. 2010, 37, 103-109.

[43] Coman G, Bahrim G. Ann. Microbiol. 2011, 61, 774-779.

[44] Soni SK, Goyal N, Gupta JK, Soni R. Starch. 2012, 64, 64-77.

[45] Bansal S, Soni SK, Harjai K, Chhibber S. J. Basic Microbiol. 2014, 54, 711-720.

[46] Rana SS, Janveja C, Soni SK. Int. J. Biol. Biomol. Agric. Food Biotechnol. Eng. 2015, 9, 164-174.

[47] Janveja C, Rana SS, Soni SK. Waste Biomass Valori. 2014, 5, 807-821.

[48] Janveja C, Rana SS, Soni SK. Int. J. Pharm. Bio. Sci. 2016, 7, 89-102.

[49] Kim JS, Kuk E, Yu KN, Kim JH, Park SJ, Lee HJ, Kim SH, Park YK, Park YH, Hwang CY, Kim YK, Lee YS, Jeong DH, Cho MH. Nanomed. 2007, 3, 95-101.

[50] Krishnan R, Arumugam V, Vasaviah SK. J. Nanomed. Nanotechnol. 2015, 6, 285.

[51] Buszewki B, Railean-Plugaru V, Pomastowski P, Rafinska K, Szultka-Mlynska M, Golinska P, Wypij M, Laskowski D, Dahm H. J. Microbiol. Immunol. Infect. 2016, 51, 45-54.

[52] Paredes D, Ortiz C, Torres R. Int. J. Nanomedicine, 2014, 9, 1717-1729.

[53] Erjaee H, Rajaian H, Nazifi S. Adv. Nat. Sci.: Nanosci. Nanotechnol. 2017, 8, 025004 (9pp).

[54] Sondi I, Salopek-Sondi B. J. Colloid Interface Sci. 2004, 275, 177-182.

[55] Castellano JJ, Shafii SM, Ko F, Donate G, Wright TE, Mannari RJ, Payne WG, Smith DJ, Robson MC. Int. Wound J. 2007, 4, 114-122.

[56] Chen X, Schluesener HJ. Toxicol. Lett. 2008, 176, 1-12.

[57] Abdel-Aziz MS, Shaheen MS, El-Nekeety AA, Abdel-Wahhab MA. J. Saudi Chem. Soc. 2014, 18, 356-363.

[58] Majeed S, Nanda A, Thirunavukarasu K. Int. J. Pharma. Technol. Res. 2014, 6, 1049-1053. 